\title{
Human Papillomavirus Infections and Cancer Stem Cells of Tumors from the Uterine Cervix
}

\author{
Jacqueline López ${ }^{1}$, Graciela Ruíz ${ }^{2}$, Jorge Organista-Nava ${ }^{3}$, Patricio Gariglio ${ }^{2}$ and \\ Alejandro García-Carrancá ${ }^{*}, 4$
}

\author{
${ }^{I}$ Programa de Doctorado en Ciencias Bioquímicas, Facultad de Química, Universidad Nacional Autónoma de México \\ (UNAM), Mexico City, Mexico \\ ${ }^{2}$ Departamento de Genética y Biología Molecular, Centro de Investigación y de Estudios Avanzados del Instituto \\ Politécnico Nacional (CINVESTAV del IPN), Mexico City, Mexico \\ ${ }^{3}$ Programa de Doctorado en Ciencias Biomédicas, Instituto de Fisiología Celular (IFC), UNAM, Mexico City, Mexico \\ ${ }^{4}$ Unidad de Investigación Biomédica en Cáncer, Instituto de Investigaciones Biomédicas, UNAM \& División de \\ Investigación Básica, Instituto Nacional de Cancerología (INCan), Secretaría de Salud (SSA), Mexico City, Mexico
}

\begin{abstract}
Different rate of development of productive infections (as low grade cervical intraepithelial neoplasias), or high grade lesions and cervical malignant tumors associated with infections of the Transformation zone (TZ) by High-Risk Human Papillomavirus (HR-HPV), could suggest that different epithelial host target cells could exist. If there is more than one target cell, their differential infection by HR-HPV may play a central role in the development of cervical cancer. Recently, the concept that cancer might arise from a rare population of cells with stem cell-like properties has received support in several solid tumors, including cervical cancer (CC). According to the cancer stem cell (CSC) hypothesis, CC can now be considered a disease in which stem cells of the TZ are converted to cervical cancer stem cells by the interplay between HR-HPV viral oncogenes and cellular alterations that are thought to be finally responsible for tumor initiation and maintenance. Current studies of CSC could provide novel insights regarding tumor initiation and progression, their relation with viral proteins and interplay with the tumor micro-environment. This review will focus on the biology of cervical cancer stem cells, which might contribute to our understanding of the mechanisms responsible for cervical tumor development.
\end{abstract}

Keywords: Cancer stem cells, cervical cancer, human papillomavirus, squamous cell carcinoma, transformation zone.

\section{INTRODUCTION}

Based on morphological observations carried out by Rudolf Virchow and Julius Cohnheim in the late $19^{\text {th }}$ century, it has been since then clearly recognized that tumors exhibit a varied cellular heterogeneity. Within a tumor, cell populations with diverse phenotypic features coexist, manifested in their morphology, surface antigens expression, differentiation proteins, among others. Also, tumor populations display functional properties reflected in different levels of proliferation as observed in vivo by colony formation assays, tumorigenicity as manifested in vivo by xeno-transplantations, different metastatic potential, and response to treatment, among the most outstanding [1].

Attempts have been made to explain this cellular heterogeneity mainly based on two models of carcinogenesis. A stochastic model stating that cellular heterogeneity arises from biologically equivalent populations as a product of selection and expansion of clones with

*Address correspondence to this author at the Laboratory of Virus \& Cancer, Instituto Nacional de Cancerología, Av. San Fernando No. 22, Sección XVI, Tlalpan, 14080, México, D.F., México; Tel: (+52) (55) 5628 0433; E-mail: carranca@biomedicas.unam.mx growth advantages. Thus, based on these assumptions, any cell within a tumor will be able to form new tumor [1]. Contrariwise, a hierarchical model stating that cellular heterogeneity arises from different phenotypic and functional populations within a tumor that contains a particular subpopulation, denominated cancer stem cells (CSC), which is the only subpopulation able to form new tumors and metastases [2]. In 2006, the consensus definition of CSC from the Workshop of the American Association for Cancer Research is a cell within a tumor that possesses the capacity to self-renew and originate all of the heterogeneous lineages of cells that comprise a tumor. Thus, CSC can only be defined experimentally by their ability to generate a continuously growing tumor. The implementation of this approach explains the use of alternative terms in the literature, such as " tumor-initiating cells" and "tumorigenic cells" to describe putative cancer stem cells [3] (for a detailed review of the biology and model of CSC see Dalerba et al., 2007[4] and Lobo et al., 2007 [5]). Since the mid-1990's, sufficient experimental evidence has been generated that supports the existence of CSC in different cancers.

Identification and isolation of CSC began in 1994; Lapidot et al. identified human Acute myeloid leukemia 
(AML)-initiating cells and fractionated them on the basis of cell-surface-marker expression [6]. Bonnet et al., using purified cell populations found that leukemia-initiating cells were exclusively CD $34^{++} \mathrm{CD}^{-} 8^{-}$[7]. Concerning solid tumors, Al-Hajj et al. identified and isolated tumorigenic cells from breast cancer, as $\mathrm{CD} 44^{+} \mathrm{CD} 24^{-/ \text {low }}$ lineage ${ }^{-}$cells [8]. Following this pioneer work, CSC have been identified in many other tumors such as brain [9], prostate [10], colon [11-13], neck and head [14], pancreas [15, 16], liver [17] and melanoma [18] (for a detailed review, see O'Brien et al. [11] and Ailles et al. [19]).

Additional to surface antigens, other methodological strategies have been widely used to identify and isolate CSC. Goodell et al., experimenting with Hoechst 33342 dye in murine bone marrow cells, found, by measuring the fluorescence of the dye at two wavelengths simultaneously, a small side population enriched with hematopoietic stem cells markers and reconstitution activity in vivo, which was termed Side Population (SP) [20]. In addition, formation of floating cell aggregates or spheres comprises another approach. In 1992, cells isolated from the striatum of the adult mouse brain were induced to proliferate in vitro, as spheres, by epidermal growth factor [21]. To date, several cancer models have been evaluated for their ability to generate CSC-enriched spheres; some of these include breast [22], melanoma [23], ovarian [24], and prostate [25].

Similar to other tissues, stem cells from normal female reproductive tract are thought to play a pivotal role in its physiology and are likely to be involved in its response to injury and disease, and could be at the origin of many tumors of the uterine cervix, by generating CSC. Cell surface antigens such as CD44, CD117, CD133, and MYD88 have been used to isolate ovarian CSC; these cells also exclude Hoechst 33342. Clonogenic epithelial and stromal cells, side population, and label-retaining cells with stem-like features from endometrial cancer tissues have been recently described (for a detailed review, see López et al. [26] and Table 1). With regard to cervical cancer (CC), over the past years, some studies have attempted to isolate CSC from primary tumors and cell lines based on cell surface markers, Hoechst staining, formation of spheres, and embryonic stem markers. However, few studies have evaluated the tumorigenic potential or have performed a more complete characterization (Table 2 ). The ability to prospectively identify CSC will facilitate the elucidation of pathways that regulate their growth and survival. Furthermore, because these cells drive tumor development, strategies designed to target this population may lead to more effective therapies.

Stem cells are defined as cells that possess the ability to perpetuate themselves by means of self-renewal, to generate mature cells of a particular tissue through differentiation of a progeny, consisting of both transiently amplifying cells and differentiated cells, and responding to homeostatic controls. These cells have been found to respond differently to therapy. Importantly stem cells, although with an unlimited capacity to self-renew, usually exhibit a limited replicating activity. Signaling pathways that normally regulate stem cell self-renewal can frequently lead to carcinogenesis when deregulated; thus, stem cells are now believed to constitute
Table 1. Markers of Human Uterine and Ovarian Cancer Stem Cells

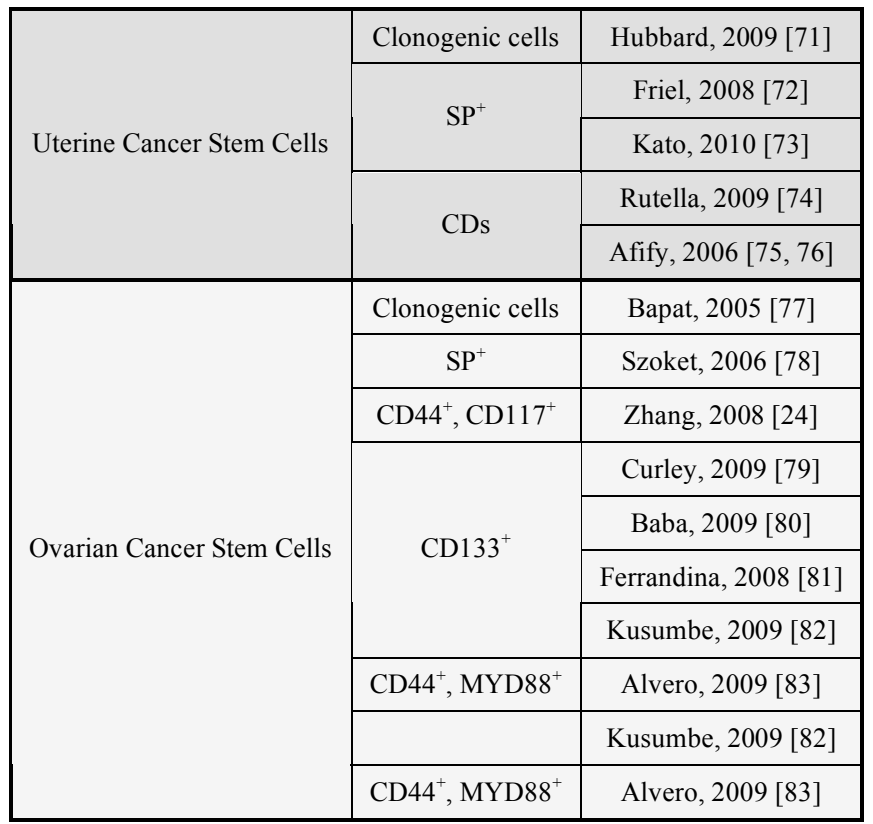

Abbreviations: CD, Cluster of differentiation; SP, Side population.

in the majority of the cases, the targets of transformation. Arguments supporting this include the fact that stem cells often persist for long periods of time, many years or the whole individuals life, in contrast to mature cells in highly proliferative tissues, which dye after short periods of time (days or weeks). This means that there is an exponential higher opportunity for mutations to accumulate in individual stem cells than in mature cell types [27]. Therefore, together with the fact that these cells may be target cells for HR-HPV infections, it is easy to imagine that this could represent a major step toward cervical carcinogenesis. HR-HPV oncogenes are well known to influence cell cycle controls leading to malignant transformation. The fact that incorporation of the viral genome into the cell nucleus requires the entry of the cell into mitosis [28]; this makes us propose that it could be possible for a viral genome to persist in a "latent" state in stem cells that do not divide for years. It is plausible that since this is an undifferentiated, multiplying cell, it makes it possible for a viral genome to incorporate into its DNA during the cell cycle (Fig. 1). A stem or progenitor cell can be the origin of tumor growth by disturbance of the asymmetric division process and can therefore be a candidate for the target cell of HR-HPV infection [2]. This particularly could explain the long latency period between viral infection and $\mathrm{CC}$ development.

\section{MARKERS OF CERVICAL CANCER STEM CELL}

The well-known process of squamous metaplasia occurring in the TZ of the cervix also suggests an important role for the reserve cell as the basal cell for columnar as well as squamous epithelial regeneration. Morphological studies have shown that reserve cells are undifferentiated, omnipotent cells that possess the capacity to undergo squamous differentiation (metaplasia). Basal cells of the ectocervical squamous epithelium are more differentiated, 
Table 2. Selective Markers of Human Epithelial Stem Cells in Cervical Cancer

\begin{tabular}{|c|c|c|c|c|c|c|c|}
\hline Sample & CSCs Markers & $\begin{array}{l}\text { \% Tumor Cells } \\
\text { with CSCs } \\
\text { Marker }\end{array}$ & $\begin{array}{l}\text { Min. } \\
\text { CSCs to } \\
\text { Engraft }\end{array}$ & $\begin{array}{l}\text { Recapitulation of } \\
\text { Original Tumor } \\
\text { Phenotype }\end{array}$ & $\begin{array}{c}\text { Serial } \\
\text { Transplant } \\
\text { Performed }\end{array}$ & Additional Assays & Ref. \\
\hline $\begin{array}{l}\text { Normal cervix } \\
\text { and CIN I-II-III }\end{array}$ & $\begin{array}{c}\text { p63 } \\
\text { CK17 }\end{array}$ & $*$ & - & - & - & - & Martens, 2004 [32] \\
\hline $\begin{array}{l}\text { Normal cervix } \\
\text { and CSCC }\end{array}$ & $\begin{array}{c}\text { Nanog } \\
\text { Musashi-1 } \\
\text { Nucleostemin }\end{array}$ & $\begin{array}{c}\text { Normal cervix }< \\
65 \% \text { and CSCC }> \\
90 \%, \text { with all } \\
\text { markers** }\end{array}$ & - & - & - & $\begin{array}{l}\text { Correlation with } \\
\text { clinicopathological } \\
\text { features }\end{array}$ & Ye, 2008 [39] \\
\hline $\begin{array}{l}\text { Normal cervix } \\
\text { and CSCC }\end{array}$ & $\begin{array}{c}\text { PSCA } \\
\text { PIWIL1 } \\
\text { TBX2 }\end{array}$ & $\begin{array}{c}\text { Normal cervix }< \\
9 \% \text { and CSCC }> \\
50 \%\end{array}$ & - & - & - & $\begin{array}{c}\text { Correlation with } \\
\text { clinicopathological } \\
\text { features and HPV16 }\end{array}$ & Liu, 2010 [40] \\
\hline $\begin{array}{l}\text { Normal cervix, } \\
\text { CIN-III, CSCC, } \\
\text { cell lines and } \\
\text { spheres }\end{array}$ & Sox 2 & \begin{tabular}{|c|} 
SiHa and spheres \\
from primary \\
cancer tissues: \\
positive. Normal \\
cervix: $25 \%$, CIN \\
III: $83 \%$, CSCC: \\
$77 \%$
\end{tabular} & $\begin{array}{l}10^{6} \mathrm{SiHa}- \\
\text { Sox } 2 \text { cells }\end{array}$ & Yes & No & $\begin{array}{c}\text { Proliferation and } \\
\text { clonogenicity of exogenous } \\
\text { Sox2 in Hela and } \\
\text { SiHa cell lines }\end{array}$ & $\mathrm{Ji}, 2010[42]$ \\
\hline $\begin{array}{c}\text { Invasive } \\
\text { carcinomas and } \\
\text { adenocarcinomas }\end{array}$ & ALDH & \begin{tabular}{|c|} 
Invasive \\
squamous \\
carcinoma $25 \%$ \\
and \\
adenocarcinomas \\
$20 \%$
\end{tabular} & - & - & - & CD133 expression & Yao, $2011[45]$ \\
\hline $\begin{array}{c}\mathrm{SiHa} \text { and } \\
\text { Ca Ski cell lines }\end{array}$ & $\begin{array}{l}\text { Spheres } \\
\text { ALDH }\end{array}$ & $\begin{array}{l}\text { CaSki: } 32 \% \\
\text { SiHa: } 0 \% \\
\text { Ca Ski: } 30 \% \\
\text { SiHa: } 24 \%\end{array}$ & - & - & - & A431 sphere characterization & $\begin{array}{c}\text { Bortolomai, } 2010 \\
{[46]}\end{array}$ \\
\hline HeLa cell line & $\begin{array}{l}\text { Spheres } \\
\text { ALDH1 } \\
\text { CD44 }\end{array}$ & $\begin{array}{c}\text { HeLa-Twist } \\
\text { elevate the level } \\
\text { of SFE, ALDH1 } \\
\text { and CD44 in } \\
\text { HeLa }\end{array}$ & - & - & - & $\begin{array}{l}\text { Activation of } \beta \text {-catenin and } \\
\text { Akt pathways by Twist and } \\
\text { suppression of CD } 44 \\
\text { expression by inhibition } \\
\text { of signaling pathways. }\end{array}$ & $\mathrm{Li}, 2011[51]$ \\
\hline $\mathrm{CSCC}$ & Spheres & - & $10^{5}$ & Yes & No & $\begin{array}{c}\text { Chemoresistance assay } \\
\text { Expression of embryonic and } \\
\text { stemness genes }\end{array}$ & Feng, $2009[52]$ \\
\hline $\begin{array}{c}\mathrm{HeLa}, \mathrm{SiHa} \\
\text { Ca Ski and C33A } \\
\text { cell lines }\end{array}$ & Spheres & HeLa: $18 \%$ & $10^{4}$ & - & No & $\begin{array}{l}\text { Chemoresistance assay and } \\
\text { gene silencing of E6 in } \\
\text { HeLa sphere-forming cells }\end{array}$ & $\mathrm{Gu}, 2011[53]$ \\
\hline $\begin{array}{c}\mathrm{HeLa}, \mathrm{SiHa} \\
\text { Ca Ski and C-4I } \\
\text { cell lines }\end{array}$ & Spheres-CD49f & $4-12 \%$ & $10^{3}$ & Yes & Yes & $\begin{array}{l}\text { Gene expression analysis and } \\
\text { radioresistance assay }\end{array}$ & López, 2012 [44] \\
\hline
\end{tabular}

Abbreviations: CSCs, Cancer stem cells; CIN, Cervical intraepithelial neoplasia; CK, Cytokeratin; CSCC, Cervical squamous cell carcinoma; PSCA, Prostate stem cell antigen; PIWIL1, Piwi-like protein 1; ALDH, Aldehyde dehydrogenase. *In normal ectocervical epithelium, p63 was restricted to the basal compartment in $76-100 \%$ of cells in all cases and CK17, was in 26-50\%. In endocervical epithelium, p63 and CK17 were not expressed. Subcolumnar reserve cells in the transitional zone and endocervix showed p63 and CK17 expression in $76-100 \%$ of cells in all cases. In CIN I and -II, the basal compartment showed p63 expression in $76-100 \%$ of cells in all cases. In CIN III lesions, staining was noted throughout the entire epithelial thickness. CK17 expression was noted in the basal compartment of all CIN lesions, irrespective of their grade, in $26-50 \%$ of cells in all cases. $* *$ Expression $>5 \%$

devoted to the formation of squamous cells, and therefore less suitable as stem cells of the cervical epithelium [29]. Previously, transcription factor p63 was described as marker for basal squamous cells and subcolumnar reserve cells in cervical epithelium [30, 31]. Martens et al. described the identification of a uterine cervical epithelium stem-cell population using monoclonal antibodies against p63 and cytokeratin 17 (CK17) in normal ectocervical, endocervical, and cervical intraepithelial neoplasia (CIN) grades I, II and III. Reserve cells and reserve cell hyperplasia showed strong staining of p63 (nuclear) and CK17 (cytoplasmatic). Cytoplasmatic staining with the monoclonal antibody against CK17 was shown in the basal compartment of ectocervical epithelium and of CIN lesions irrespective of their grade. Reserve cells and reserve cell hyperplasia showed strong expression in all cases [32]. Additionally, in the adult cervix, reserve cells demonstrate a specific phenotype that expresses, among others, the BCL-2 gene [33]. In all cases, p63 was strongly expressed in the basal layer of the 


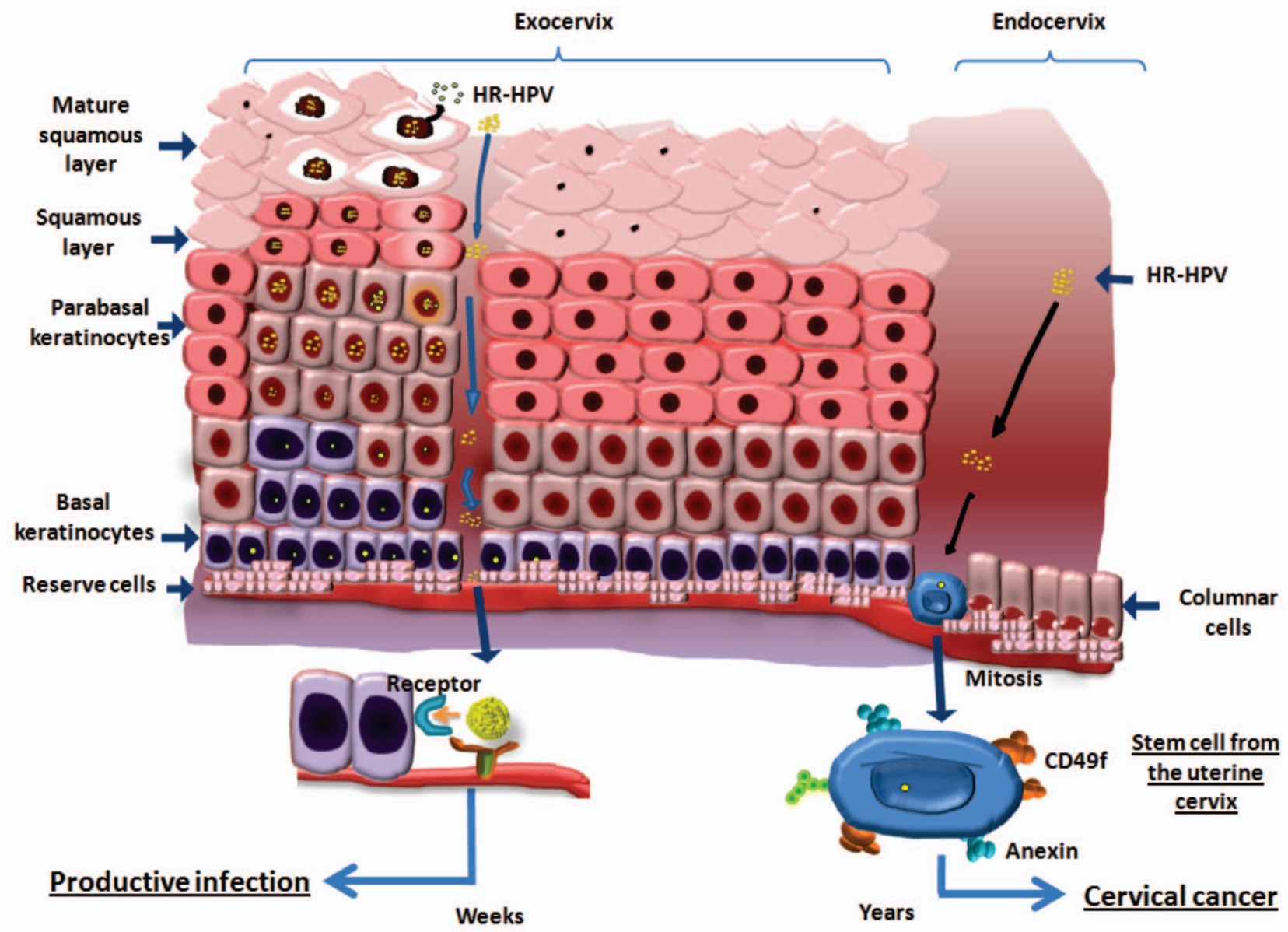

Fig. (1). Two different consequences proposed for infection of basal cells or cervical stem cells with High Risk-Human Papillomavirus (HRHPV). One area where cervical stem cells are likely to be found comprises the squamocolumnar junction, where the ecto- and the endocervix meet and where reserve cells are frequently found. We propose that HR-HPV infect in the cervix both basal and stem cells, in the former leading to a productive infection within weeks and in the latter, probably generating cancer years later.

ectocervical epithelia and in the basal layers of CIN lesions irrespective of grade.

According to other studies [34, 35], p63 was expressed in basal and suprabasal cells of mature and immature metaplastic squamous cells and in subcolumnar reserve cells of the $\mathrm{TZ}$ in the uterine cervix. In normal cervix, the transition from squamous to columnar cells coincided with loss of p63 expression, whereas its expression was inversely correlated with both squamous cell maturation and nonsquamous cell differentiation. Recently, it was shown that p63 induces a stem cell phenotype in the MCF7 breast carcinoma cell line and that it could be a marker of breast $\mathrm{CSC}$; in this cell line, p63 led to increased cancer cell proliferation, clonogenicity, anchorage-independent growth, and the incidence of tumor xenografts formed in vivo in immunosuppressed mice [36]. These results suggest that p63 might be a tumor-initiating transcription factor in $\mathrm{CC}$ and that p63 is one of the possible markers of CSC in epithelial tissues. Recently, Mighty et al. found that, upon differentiation of normal keratinocytes, p63 levels decreased rapidly, while higher levels were retained in HPV-positive cells, and that late p63 gene expression regulates the expression of cell cycle regulators, such us, cyclin A, cyclin B1, cdk1, and cdc25c. In addition, activation of the DNA repair pathway was necessary for genome amplification, and the expression of two members, BRCA2 and RAD51, was altered in the absence of p63 in HPV-positive cells [37].

Furthermore, Martens et al. focused on the distribution pattern and marker profile of reserve cells along the entire length of the adult endocervical canal. The authors employed sagital sections from 10 normal uteri, comprising the region from ectocervix to lower uterine cavity; these sections were histologically examined and immunostained for p63, bcl-2, and CK 5, 7, 8, and 17. They observed that reserve cells are present in all investigated cervices along the entire cervical canal. The concentration of subglandular reserve cells was highest near the squamocolumnar junction and in the upper third of the cervix. These authors found a discontinuous distribution pattern of reserve cells in all of the uterine cervix; on the basis of their marker profile, they defined two subpopulations of reserve cells in the adult human uterine cervical epithelium: a CK17-positive subpopulation in the lower part of the cervical canal with progenitor cells for the squamous and columnar epithelium, and a subpopulation of 
CK17-negative reserve cells with progenitor cells only for columnar epithelium [38].

The stem cell-abundant proteins Nanog, Nucleostemin (NS) and Musashi1 (Msi1) are highly expressed in undifferentiated embryonic stem cells and negatively regulate stem-cell differentiation, proliferation, and asymmetric division, respectively. Ye et al. examined the expression of Nanog, NS, and Msil in cervical epithelial lesions of varying severity and in cervical carcinomas by immunohistochemical analysis and assessed their association with several prognostic variables. These findings indicate that Nanog, NS, and Msil may be involved in carcinogenesis of the cervix and the progression of cervical carcinoma. However, there were no positive correlations between Nanog, NS, and Msil expression levels and the clinical pathological prognostic factors analyzed, indicating that overexpression of these three stem cell-abundant proteins in the cervical epithelium is not related with the prognosis of cervical carcinoma [39].

Few reports have emerged concerning the expression of stem cell-associated genes PSCA and PIWIL1 and transcriptional factor $T B X 2$ in cervical squamous cell carcinoma (CSCC). For example, Liu et al. investigated the expression of these CSC-associated gene products in CSCC and their relationship with HPV16 in order to provide some basic information on potential molecular mechanisms of the effect of HPV16 infection on cervical carcinogenesis. They evaluated the expression of PSCA, PIWIL1, TBX2 and HPV16 E7 in 59 CSCC and Matched adjacent normal cervix (MANC), employing the streptavidin-peroxidase method. PSCA, PIWIL1 and TBX2 expression rates in MANC were $6(3 / 52), 8(4 / 52)$, and $2 \%(1 / 52)$, respectively, but those in CSCC comprised 62 (32/52), 75 (39/52), and 52\% (27/52), respectively. However, the increased expression of PSCA, PIWIL1, and TBX2 observed in CSCC had no correlation with the patient's age or histological grade. Elevated expression of PSCA and PIWIL1 was associated with invasion of CSCC, and up-regulated expression of TBX2 had a positive association with lymph node metastasis. HPV16 had a statistical positive correlation with PSCA, PIWIL1, and TBX2 in CSCC, which raised the question of whether HPV16 viral oncoproteins might be involved in upregulating the expression of CSC-associated genes and suggests a complex molecular mechanism for the role of HPV16 infection during cervical carcinogenesis of CSCC [40]. Recently, Ye et al. identified a Piwil2-like (PL2L) protein that is predominantly expressed in human primary and metastatic cervical cancers in association with Nuclear factor-kappa beta (NF-k $\beta$ ) that promote tumorigenesis [41]. Further researches should be conducted utilizing a cell or animal model to demonstrate a definite role for HPV16 in the overexpression of PSCA, PIWIL1, PL2L, and TBX2.

SOX2 is a member of the SOX gene family that encodes transcription factors expressed in several phases of embryonic development, which affects cell fate and differentiation. Ji et al. examined the expression of SOX2 in normal and pathologic cervical tissues. They also compared SOX2 expression in CC tumorspheres and its differentiated cells. They demonstrated that SOX2 may play an important role in tumorigenesis and suggest a possible therapeutic target molecule in CC [42].
Another marker associated with the pluripotent state of cells comprising the inner cell mass of pre-implantation embryos and that has been known to play a critical role in the maintenance of the pluripotency of embryonic stem cells is the POU-domain transcription factor OCT4. Cantz et al. were unable to detect staining of the OCT4 transcription factor in the nucleus in the cervical carcinoma cell line HeLa by immunofluorescence using two different monoclonal antibodies [43].

Another useful CSC marker is the Aldehyde dehydrogenase (ALDH1), a detoxifying enzyme responsible for the oxidation of retinol into retinoic acid and which plays a role in the early stem-cell differentiation. When expression of ALDH1 in cervical carcinoma was evaluated by Yao et al. by immunohistochemistry of 23/89 samples of invasive squamous carcinoma and 4/20 samples of adenocarcinomas, they were found to exhibit immunoreactivity to ALDH1. They found lower levels of CD133 in HeLa, SiHa and CaSki cervical cell lines similar to showed by López et al. (2012) [44], define ALDH1 as a marker for identifying CSC and suggest that cervical carcinoma contains a small subpopulation of cells with a cancer stem cell-like phenotype [45].

\section{CHARACTERIZING CERVICAL STEM CELLS USING SPHERE FORMATION ASSAY}

Bortolomai et al. compared CaSki, SiHa and A431 cancer cell lines for sphere-forming efficiency and intrinsic ALDH enzymatic activity. A431 cells exhibited the highest fraction of ALDH-positive cells and good correlation between ALDH positivity and sphere forming efficiency. Therefore, they selected the A431 cell line as a model with which to evaluate the experimental procedures adopted for CSC characterization in tumor cell lines [46]. However, to the best of our knowledge, A431 cells were established from an epidermoid carcinoma in the vulva of an 85-year-old female patient [47].

Studies deriving from many laboratories indicate that Epithelial-mesenchymal transition (EMT) can endow cells with stem cell-like characteristics [48-50]. Li et al. induced EMT in breast cancer MCF7 and CC HeLa cells with expression of Twist, a key transcriptional factor of EMT. They also found that cancer stem cell-like traits, such as tumorsphere formation and the expression of ALDH1 and CD44 were significantly elevated in Twist-overexpressing cells. Interestingly, the authors showed that $\beta$-catenin and Akt pathways were activated in these Twist-overexpressing cells. Activation of $\beta$-catenin correlated with CD44 expression. Knockdown of $\beta$-catenin expression and inhibition of the Akt pathway greatly suppressed the expression of CD44. This study provides several new insights into the regulation of EMT and the cell differentiation program. First, these results indicate that activation of $\beta$-catenin and Akt pathways is critical for the maintenance of EMT-associated stem cell-like properties. Second, these results suggest that targeting the $\beta$-catenin and Akt pathways can suppress EMT-associated stem cell-like properties [51].

A CSC population from primary carcinoma of the cervix uteri was recently identified. Cervical carcinoma from 19 patients was disaggregated and subjected to stem cell- 
selective growth conditions. Eight of 19 tumor-derived cultures encompassed CSC capable of self-renewal and extensive proliferation as clonal non-adherent spherical clusters. Cell markers of spheroids were identified as CD44 $\mathrm{CK} 17^{+}$. Cell survival assays showed that sphere-forming cells were only $48 \%$ inhibited by doxorubicin compared with non-sphere forming cells, which were $78 \%$ inhibited by this drug. To investigate the tumorigenicity of these CSC, xenoengraftment of $1 \times 10^{5}$ dissociated spheroid cells allowed full recapitulation of the original tumor, whereas the same amount of tumor cells without non-adherent spheroid selection remained non-tumorigenic. Stem properties of these spheroid cells were further established by RT-PCR and WB, demonstrating the expression of embryonic and adult stemness-related gene products (OCT4, PIWIL2, C-MYC, STAT3, and SOX2) [52].

Employing a sphere culture method that favors the growth of self-renewal cells, $\mathrm{Gu}$ et al. isolated Sphereforming cells (SFC) from CC cell lines HeLa and $\mathrm{SiHa}$. HeLa-SFC were more tumorigenic, as evidenced by the growth of tumors following injection of immunodeficient mice with $1 \times 10^{4}$ cells, compared with $1 \times 10^{6}$ parental HeLa cells that were required to grow similarly sized tumors within the same time frame. They further demonstrated that HeLa-SFC expressed a higher level (6.9-fold) of the HPV E6 oncogene, compared with that of parental HeLa cells. Gene silencing of E6 with a lentiviral-short-hairpin RNA inhibited HeLa-SFC sphere formation and cell growth. The authors then measured the expression of self-renewal genes, Transformation growth factor- $\beta$ (TGF- $\beta$ ), and the leukemiainhibitory factor in short-hairpin RNA-transduced HeLaSFC and found that expression of all three TGF- $\beta$ isoforms was significantly down-regulated, while the leukemiainhibitory factor remained unchanged. This result suggests that E6 silencing exerts a specific effect on the expression of self-renewal gene $T G F-\beta$ [53]. To prove down-regulation of TGF- $\beta$ after E6 silencing, the authors measured the expression of both $\mathrm{H}-R A S$ and $\mathrm{K}-R A S$ genes, downstream components of the TGF- $\beta$ pathway. RAS expression was also markedly decreased after TGF- $\beta$ down-regulation, suggesting that the growth-inhibitory effect could be via the TGF- $\beta$ pathway. Gu et al. postulate that downregulation of the PI3K/Akt pathway after E6 silencing comprise the link that indirectly affects $T G F-\beta$ expression, but this requires further investigation [53].

Recently, López et al. characterized a self-renewing subpopulation of CSC among four well-known human cancer-derived cell lines (HeLa, SiHa, Ca Ski, and C-4I) and found that these express the CSC markers characteristic of the female reproductive system including CD44, ITGB1 (CD29), PSCA, NT5E (CD73), ENG (CD105), MYC (cMyc), PCGF4 (BMI-1), and ABCG2. Other epithelial CSC markers found included ITGB6, ALCAM (CD166), and MET (c-Met)[44]. Interestingly, components of the doublestrand break DNA repair machinery and genes involved in the metabolism of reactive oxygen species were also upregulated and indeed, dose-dependent radiation assays indicated that CSC-enriched populations exhibit increased resistance to ionizing radiation. They found that CSC enriched as spheroids could generate reproducible tumor phenotypes in immunodeficient nu-nu mice and could be propagated serially. Injection of $1 \times 10^{3}$ dissociated cells from spheroids induced tumors in the majority of animals, whereas injection of monolayer-grown $1 \times 10^{5}$ cells remained nontumorigenic. Sphere-derived CSC highly expressed CD49f. Interestingly, CD49f (ITGA6), an alpha-6 integrin, has been postulated as the primary receptor protein in natural HR-HPV infection [54-57]; thus, it was postulated that adult reserve cells with CD49f expression could be preferentially targeted by HR-HPV types during cervical carcinogenesis. In addition, EMT transition-associated markers were found highly expressed in spheroid cells [44].

\section{CERVICAL CANCER AND HUMAN PAPILLOMA- VIRUS INFECTIONS}

Cancer of the uterine cervix is a leading cause of death in women. It is the second most frequent type of cancer in women worldwide, preceded only by breast cancer [58]; GLOBOCAN 2008 reported that each year, 530,000 [59] women worldwide are diagnosed with invasive $\mathrm{CC}$ and more than one half of these die from this disease. Eighty percent of these deaths occur in developing countries, and $\mathrm{CC}$ remains a cause of significant morbidity and mortality. It is therefore essential to develop a deeper understanding of the biology of this disease in order to find more effective therapies, because the majority of patients with $\mathrm{CC}$ receive standard radiotherapy and chemotherapy. However, clinical outcomes vary significantly and are difficult to predict. CC is the result of a multistep process that involves the transformation of the normal cervical epithelium into a pre-neoplastic cervical intraepithelial neoplasm that can subsequently transform into invasive cancer [60]. Many studies have shown the tight association between development of $\mathrm{CC}$ and infection with HR-HPV [61]. Cell cycle, apoptosis, and proliferation are influenced by molecular interactions of HPV early gene products, particularly E6 and E7 with cellular proteins. These oncogenic proteins have the ability to bind many host regulatory proteins, among the most important of them leading to degradation and functional inactivation of the p53 tumor suppressor and retinoblastoma gene proteins [62]. In the case of the targets for viral infection, it has been suggested that both the basal and stem cells of the cervical epithelium could constitute target for infections by HPV.

Persistence infections with a HR-HPV are a prerequisite for cervical carcinoma development. It was recently found that entry of these viruses is dependent upon a specific proteolytic event that occurs prior to viral endocytosis. Specifically, a proprotein convertase, furin or proprotein convertase $5 / 6$, must cleave the minor capsid protein for infection to proceed [63].

The entry of HPV in vitro is initiated by binding to a cell surface receptor in contrast to the in vivo situation where the basement membrane has recently been identified as the primary site of virus binding. Binding of HPV triggers conformational changes, which affect both capsid proteins L1 and L2, and such changes are a prerequisite for interaction with the elusive uptake receptor. Furthermore, the productive entry of HPV is a process that occurs slowly and asynchronously and it is characterized by an unusually extended residence on the cell surface [64].

It has been shown that in vivo HPV virions bind initially to the base membrane prior to transfer to the basal keratinocyte cell surface [65]. Glycosaminoglycans, 
frequently found in the extracellular matrix and on the surface of most cells, especially heparan sulfate, have been suggested as initial attachment receptors for HPV [66, 67].

The fact that HR-HPV could target both basal and stem cells of the cervical epithelium, together with the fact the that the entry of HPV DNA to the cell nucleus has been shown to be dependent of the cell cycle, particularly the pass through mitosis has fundamental implications. We propose that the targets for transforming events, caused by HR-HPV infection in the uterine cervical epithelium are stem cells; this is in contrast to the majority of infections where the target of productive infections would be the basal cells, progenitors of normal stem cells and with transiently capacity for replication, that is extended by viral factors interacting with their targets (Fig. 1).

Indeed, infection by HPV has been shown to be dependent on CDK1 activity, consistent with the idea that the final delivery of the HPV genome into the nucleus will depend ultimately on nuclear envelope breakdown [68]. CDK1 activity is correlated with nuclear envelope breakdown and its inhibition prevents this to occur. Another possibility is that nuclear entry of HPV is dependent on the reorganization of the cytoplasmic microtubules to support the formation of the mitotic spindle [69].

In addition, Roberts et al. have observed that the columnar epithelium adjacent to the TZ shows a marked increase in sensitivity to infection when disrupted by N-9, a non-ionic, membrane- active surfactant, widely used as spermicidal and known to disrupt the normal architecture of animal and human genital epithelium $[65,70]$. This supports the idea that cervical stem cells particularly those of the TZ could be targets for HR-HPV induced transformation events.

\section{CONCLUSIONS}

Although limited, the evidence that supports the existence of CSC populations in cervical tumors is relatively convincing. These findings serve as a basis from which to examine the functional parameters of the cancer stem/progenitor cell population and its contribution to the development and progression of CC. However, there remains a need to identify definitive markers for additional selective CSC isolation and enrichment, as well as the need to improve the precision and reproducibility of markers. Transgenic animals and xenograft model systems for human cells engraftment should also be implemented and optimized in order to examine the hallmark characteristics of putative cervical cancer stem cells.

\section{PERSPECTIVES}

A complete understanding of the nature of human cervical cancer stem cells that have the potential to contribute significantly to $\mathrm{CC}$ development is needed, as well as their relation with HR-HPV infections. This knowledge will certainly allow us to better develop novel strategies for more clinically effective diagnosis of cervical cancer and its treatment.

\section{CONFLICT OF INTEREST}

The authors confirm that this article content has no conflicts of interest.

\section{ACKNOWLEDGEMENTS}

We acknowledge generous support from Instituto de Ciencia y Tecnología del Gobierno del Distrito Federal (ICyT-GDF; GI/PIFUTP08-142 to AGC), Consejo Nacional de Ciencia y Tecnología-México (CONACYT-México grants 44071 and 127822 to AGC), Programa de Apoyo a Proyectos de Investigación e Innovación Tecnológica de la Universidad Nacional Autónoma de México", (PAPIITUNAM; IN2264 08 to AGC), and Instituto Nacional de Cancerología, Secretaría de Salud, México and technical assistance from Alvarez-Rios E.

\section{REFERENCES}

[1] Nowell PC. The clonal evolution of tumor cell populations. Science 1976; 194: 23-8.

[2] Reya T, Morrison SJ, Clarke MF, Weissman IL. Stem cells, cancer, and cancer stem cells. Nature 2001; 414: 105-11.

[3] Clarke MF, Dick JE, Dirks PB, et al. Cancer Stem Cells-Perspectives on Current Status and Future Directions: AACR Workshop on Cancer Stem Cells. Cancer Res 2006; 66: 9339-44.

[4] Dalerba P, Cho RW, Clarke MF. Cancer stem cells: models and concepts. Annu Rev Med 2007; 58: 267-84.

[5] Lobo NA, Shimono Y, Qian D, Clarke MF. The biology of cancer stem cells. Annu Rev Cell Dev Biol 2007; 23: 675-99.

[6] Lapidot T, Sirard C, Vormoor J, et al. A cell initiating human acute myeloid leukaemia after transplantation into SCID mice. Nature 1994; 367: 645-48.

[7] Bonnet D, Dick JE. Human acute myeloid leukemia is organized as a hierarchy that originates from a primitive hematopoietic cell. Nat Med 1997; 3: 730-7.

[8] Al-Hajj M, Wicha MS, Benito-Hernandez A, Morrison SJ, Clarke MF. Prospective identification of tumorigenic breast cancer cells. Proc Natl Acad Sci USA 2003; 100: 3983-88.

[9] Singh SK, Hawkins C, Clarke ID, et al. Identification of human brain tumour initiating cells. Nature 2004; 432: 396-401.

[10] Collins AT, Berry PA, Hyde C, Stower MJ, Maitland NJ. Prospective Identification of Tumorigenic Prostate Cancer Stem Cells. Cancer Res 2005; 65: 10946-51.

[11] O'Brien CA, Kreso A, Dick JE. Cancer stem cells in solid tumors: an overview. Semin Radiat Oncol 2009; 19: 71-7.

[12] Dalerba P, Dylla SJ, Park I-K, et al. Phenotypic characterization of human colorectal cancer stem cells. Proc Natl Acad Sci USA 2007; 104: 10158-63.

[13] Ricci-Vitiani L, Lombardi DG, Pilozzi E, et al. Identification and expansion of human colon-cancer-initiating cells. Nature 2007; 445: 111-5.

[14] Prince ME, Sivanandan R, Kaczorowski A, et al. Identification of a subpopulation of cells with cancer stem cell properties in head and neck squamous cell carcinoma. Proc Natl Acad Sci USA 2007; 104: 973-78.

[15] Li C, Heidt DG, Dalerba P, et al. Identification of Pancreatic Cancer Stem Cells. Cancer Res 2007; 67: 1030-7.

[16] Hermann PC, Huber SL, Herrler T, et al. Distinct Populations of Cancer Stem Cells Determine Tumor Growth and Metastatic Activity in Human Pancreatic Cancer. Cell Stem Cell 2007; 1: 31323.

[17] Yang ZF, Ho DW, Ng MN, et al. Significance of CD90+ Cancer Stem Cells in Human Liver Cancer. Cancer Cell 2008; 13: 153-66.

[18] Schatton T, Murphy GF, Frank NY, et al. Identification of cells initiating human melanomas. Nature 2008; 451: 345-49.

[19] Ailles LE, Weissman IL. Cancer stem cells in solid tumors. Curr Opin Biotechnol 2007; 18: 460-66.

[20] Goodell MA, Brose K, Paradis G, Conner AS, Mulligan RC. Isolation and functional properties of murine hematopoietic stem cells that are replicating in vivo. J Exp Med 1996; 183: 1797-806.

[21] Reynolds BA, Weiss S. Generation of neurons and astrocytes from isolated cells of the adult mammalian central nervous system. Science 1992; 255: 1707-10.

[22] Ponti D, Costa A, Zaffaroni $\mathrm{N}$, et al. Isolation and In vitro Propagation of Tumorigenic Breast Cancer Cells with Stem/Progenitor Cell Properties. Cancer Res 2005; 65: 5506-11. 
[23] Fang D, Nguyen TK, Leishear K, et al. A Tumorigenic Subpopulation with Stem Cell Properties in Melanomas. Cancer Res 2005; 65: 9328-37.

[24] Zhang S, Balch C, Chan MW, et al. Identification and Characterization of Ovarian Cancer-Initiating Cells from Primary Human Tumors. Cancer Res 2008; 68: 4311-20.

[25] Garraway IP, Sun W, Tran CP, et al. Human prostate sphereforming cells represent a subset of basal epithelial cells capable of glandular regeneration in vivo. Prostate 2010; 70: 491-501.

[26] López J, Valdez-Morales F, Benítez-Bribiesca L, Cerbón M, García Carrancá A. Normal and cancer stem cells of the human female reproductive system. Eur J Obstet Gynecol Reprod Biol 2012; in preparation.

[27] Pierce GB. Neoplasms, differentiations and mutations. Am J Pathol 1974; 77: 103-18.

[28] Schelhaas M, Weber S, Kuhbacher A. Human Papillomavirus type 16 nuclear entry depends on mitosis: 2011. Proceedings of the 27th International Papillomavirus Conference and Clinical Worlkshop 2011 September 17-22. Berlín, Germany 2011.

[29] Smedts F, Ramaekers F, Leube RE, Keijser K, Link M, Vooijs P. Expression of keratins 1, 6, 15, 16, and 20 in normal cervical epithelium, squamous metaplasia, cervical intraepithelial neoplasia, and cervical carcinoma. Am J Pathol 1993; 142: 403-12.

[30] Ince TA, Cviko AP, Quade BJ, et al. p63 Coordinates anogenital modeling and epithelial cell differentiation in the developing female urogenital tract. Am J Pathol 2002; 161: 1111-7.

[31] Quade BJ, Yang A, Wang Y, et al. Expression of the p53 Homologue p63 in Early Cervical Neoplasia. Gynecol Oncol 2001; 80: $24-9$.

[32] Martens JE, Arends J, Van Der Linden PJQ, De Boer BAG, Helmerhorst TJM. Cytokeratin 17 and p63 are Markers of the HPV Target Cell, the Cervical Stem Cell. Anticancer Res 2004; 24: 77176.

[33] Ter Harmsel B, Smedts F, Kuijpers J, Jeunink M, Trimbos B, Ramaekers F. BCL-2 immunoreactivity increases with severity of CIN: a study of normal cervical epithelia, CIN, and cervical carcinoma. J Pathol 1996; 179: 26-30.

[34] Wang T-y, Chen B-f, Yang Y-c, et al. Histologic and immunophenotypic classification of cervical carcinomas by expression of the p53 homologue p63: A study of 250 cases. Hum Pathol 2001; 32: 479-86.

[35] Lin Z, Liu M, Li Z, Kim C, Lee E, Kim I. Delta Np63 protein expression in uterine cervical and endometrial cancers. J Cancer Res Clin Oncol 2006; 132: 811-6.

[36] Du Z, Li J, Wang L, et al. Overexpression of Np63 induces a stem cell phenotype in MCF7 breast carcinoma cell line through the Notch pathway. Cancer Sci 2010; 101: 2417-24.

[37] Mighty KK, Laimins LA. p63 Is Necessary for the Activation of Human Papillomavirus Late Viral Functions upon Epithelial Differentiation. J Virol 2011; 85: 8863-9.

[38] Martens JE, Smedts FMM, Ploeger D, et al. Distribution pattern and marker profile show two subpopulations of reserve cells in the endocervical canal. Int J Gynecol Pathol 2009; 28: 381-8.

[39] Ye F, Zhou C, Cheng Q, Shen J, Chen H. Stem-cell-abundant proteins Nanog, Nucleostemin and Musashil are highly expressed in malignant cervical epithelial cells. BMC Cancer 2008; 8: 10812.

[40] Liu W-K, Jiang X-Y, Zhang Z-X. Expression of PSCA, PIWIL1 and TBX2 and its correlation with HPV16 infection in formalinfixed, paraffin-embedded cervical squamous cell carcinoma specimens. Arch Virol 2010; 155: 657-63.

[41] Ye Y, Yin D, Chen L, et al. Identification of Piwil2-Like (PL2L) Proteins that Promote Tumorigenesis. PLoS One 2010; 5: e13406.

[42] Ji J, Zheng PS. Expression of Sox2 in human cervical carcinogenesis. Hum Pathol 2010; 41: 1438-47.

[43] Cantz T, Key G, Bleidissel M, et al. Absence of OCT4 expression in somatic tumor cell lines. Stem Cells 2008; 26: 692-7.

[44] Lopez J, Poitevin A, Mendoza-Martinez V, Perez-Plasencia C, Garcia-Carranca A. Cancer-initiating cells derived from established cervical cell lines exhibit stem-cell markers and increased radioresistance. BMC Cancer 2012; 12: 48.

[45] Yao T, Chen Q, Lin Z, Zhou H, Zhang B. The expression of ALDH1 in cervical carcinoma. Med Sci Monit 2011; 17: 21-6.

[46] Bortolomai I, Canevari S, Facetti I, et al. Tumor initiating cells: Development and critical characterization of a model derived from the A431 carcinoma cell line forming spheres in suspension. Cell Cycle 2010; 9: 1194-206.

[47] Giard D, Aaronson S, Todaro G, et al. In vitro cultivation of human tumors: establishment of cell lines derived from a series of solid tumors. J Natl Cancer Inst 1973; 51: 1417-23.

[48] Morel A-P, Lièvre M, Thomas C, Hinkal G, Ansieau S, Puisieux A. Generation of Breast Cancer Stem Cells through EpithelialMesenchymal Transition. PLoS One 2008; 3: e2888.

[49] Kurrey NK, Jalgaonkar SP, Joglekar AV, et al. Snail and Slug Mediate Radioresistance and Chemoresistance by Antagonizing p53-Mediated Apoptosis and Acquiring a Stem-Like Phenotype in Ovarian Cancer Cells Stem Cells 2009; 27: 2059-68.

[50] Mani SA, Guo W, Liao MJ, et al. The epithelial-mesenchymal transition generates cells with properties of stem cells. Cell 2008; 133: 704-15

[51] Li J, Zhou B. Activation of beta-catenin and Akt pathways by Twist are critical for the maintenance of EMT associated cancer stem cell-like characters. BMC Cancer 2011; 11: 49.

[52] Feng D, Peng C, Li C, et al. Identification and characterization of cancer stem-like cells from primary carcinoma of the cervix uteri. Oncol Rep 2009; 22: 1129-34.

[53] Gu W, Yeo E, McMillan N, Yu C. Silencing oncogene expression in cervical cancer stem-like cells inhibits their cell growth and selfrenewal ability. Cancer Gene Ther 2011; 18: 897-905.

[54] Yoon CS, Kim KD, Park SN, Cheong SW. Alpha 6 Integrin is the main receptor of Human Papillomavirus Type 16 VLP. Biochem Biophys Res Commun 2001; 283: 668-73.

[55] Fothergill T, McMillan NAJ. Papillomavirus virus-like particles activate the PI3-kinase pathway via alpha- 6 beta-4 integrin upon binding. Virology 2006; 352: 319-28.

[56] Branca M, Giorgi C, Ciotti M, et al. Relationship of up-regulation of 67-kd laminin receptor to grade of cervical intraepithelial neoplasia and to high-risk HPV types and prognosis in cervical cancer. Acta Cytol 2006; 50: 6-15.

[57] Sun X, Cai H, Qian H, et al. Mesenchymal stem cells isolated from human uterine cervix cancer tissues. Cell Biol Int 2011; 35: 119-23. Ferenczy A, Franco E. Persistent human papillomavirus infection and cervical neoplasia. Lancet Oncol 2002; 3: 11-6.

[59] Ferlay J, Shin H-R, Bray F, Forman D, Mathers C, Parkin DM. Estimates of worldwide burden of cancer in 2008: GLOBOCAN 2008. Int J Cancer 2010; 127: 2893-917.

[60] Walboomers JMM, Jacobs MV, Manos MM, et al. Human papillomavirus is a necessary cause of invasive cervical cancer worldwide. J Pathol 1999; 189: 12-9.

[61] Zur Hausen H. Papillomavirus infections--a major cause of human cancers. Biochim Biophys Acta 1996; 1288: F55-78.

[62] Harald Zur H. Papillomaviruses Causing Cancer: Evasion From Host-Cell Control in Early Events in Carcinogenesis. J Natl Cancer Inst 2000; 92: 690-8

[63] Day PM, Schiller JT. The role of furin in papillomavirus infection. Future Microbiol 2009; 4: 1255-62.

[64] Horvath CA, Boulet GA, Renoux VM, Delvenne PO, Bogers JP. Mechanisms of cell entry by human papillomaviruses: an overview. Virol J 2010; 7: 11.

[65] Roberts JN, Buck CB, Thompson CD, et al. Genital transmission of HPV in a mouse model is potentiated by nonoxynol- 9 and inhibited by carrageenan. Nat Med 2007; 13: 857-61.

[66] Joyce JG, Tung JS, Przysiecki CT, et al. The L1 major capsid protein of human papillomavirus type 11 recombinant virus-like particles interacts with heparin and cell-surface glycosaminoglycans on human keratinocytes. J Biol Chem 1999; 274: 5810-22.

[67] Giroglou T, Florin L, Schafer F, Streeck RE, Sapp M. Human papillomavirus infection requires cell surface heparan sulfate. J Virol 2001; 75: 1565-70

[68] Pyeon D, Pearce SM, Lank SM, Ahlquist P, Lambert PF. Establishment of human papillomavirus infection requires cell cycle progression. PLoS Pathog 2009; 5: e1000318.

[69] Luders J, Stearns T. Microtubule-organizing centres: a reevaluation. Nat Rev Mol Cell Biol 2007; 8: 161-7.

[70] Niruthisard S, Trisukosol D. Male sexual behavior as risk factor in cervical cancer. J Med Assoc Thai 1991; 74: 507-12.

[71] Hubbard SA, Friel AM, Kumar B, Zhang L, Rueda BR, Gargett CE. Evidence for Cancer Stem Cells in Human Endometrial Carcinoma. Cancer Res 2009; 69: 8241-48. 
[72] Friel AM, Sergent PA, Patnaude C, et al. Functional analyses of the cancer stem cell-like properties of human endometrial tumor initiating cells. Cell Cycle 2008; 7: 242-49.

[73] Kato K, Takao T, Kuboyama A, et al. Endometrial Cancer SidePopulation Cells Show Prominent Migration and Have a Potential to Differentiate into the Mesenchymal Cell Lineage. Am J Pathol 2010; 176: 381-92.

[74] Rutella S, Bonanno G, Procoli A, et al. Cells with Characteristics of Cancer Stem/Progenitor Cells Express the CD133 Antigen in Human Endometrial Tumors. Clin Cancer Res 2009; 15: 4299-311.

[75] Afify AM, Craig S, Paulino AFG. Temporal variation in the distribution of hyaluronic acid, CD44s, and CD44v6 in the human endometrium across the menstrual cycle. Appl Immunohistochem Mol Morphol 2006; 14: 328-33.

[76] Afify AM, Craig S, Paulino AFG, Stern R. Expression of hyaluronic acid and its receptors, CD44s and CD44v6, in normal, hyperplastic, and neoplastic endometrium. Ann Diagn Pathol 2005; 9: 312-8.

[77] Bapat SA, Mali AM, Koppikar CB, Kurrey NK. Stem and Progenitor-Like Cells Contribute to the Aggressive Behavior of Human Epithelial Ovarian Cancer. Cancer Res 2005; 65: 3025-9.
[78] Szotek PP, Pieretti-Vanmarcke R, Masiakos PT, et al. Ovarian cancer side population defines cells with stem cell-like characteristics and Mullerian Inhibiting Substance responsiveness. Proc Natl Acad Sci USA 2006; 103: 11154-9.

[79] Curley MD, Therrien VA, Cummings CL, et al. CD133 Expression defines a tumor initiating cell population in primary human ovarian cancer. Stem Cells. 2009; 27: 2875-83.

[80] Baba T, Convery PA, Matsumura N, et al. Epigenetic regulation of CD133 and tumorigenicity of $\mathrm{CD} 133+$ ovarian cancer cells. Oncogene. 2009; 28: 209-18.

[81] Ferrandina G, Bonanno G, Pierelli L, et al. Expression of CD133-1 and CD133-2 in ovarian cancer. Int J Gynecol Cancer 2008; 18 : 506-14.

[82] Kusumbe AP, Mali AM, Bapat SA. CD133-Expressing Stem Cells Associated with Ovarian Metastases Establish an Endothelial Hierarchy and Contribute to Tumor Vasculature. Stem Cells 2009; 27: 498-508.

[83] Alvero $\mathrm{AB}$, Chen $\mathrm{R}, \mathrm{Fu} \mathrm{H}-\mathrm{H}$, et al. Molecular phenotyping of human ovarian cancer stem cells unravels the mechanisms for repair and chemoresistance. Cell Cycle 2009; 8: 158-66.

This is an open access article licensed under the terms of the Creative Commons Attribution Non-Commercial License (http: //creativecommons.org/licenses/by$\mathrm{nc} / 3.0 /$ ) which permits unrestricted, non-commercial use, distribution and reproduction in any medium, provided the work is properly cited. 